\title{
Effectiveness of the Dedicated Substance Abuse Treatment Unit in the Regina Correctional Centre: A seven-year retrospective analysis
}

\author{
Elan Paluck, ${ }^{*}$ Dorothy Banka, ${ }^{\dagger}$ Michelle C.E. McCarron, ${ }^{\star}$ and Mamata Pandey*
}

\begin{abstract}
The Dedicated Substance Abuse Treatment Unit (DSATU) is a specialized unit at the Regina Correctional Centre (RCC) that began providing comprehensive in-patient addiction treatment to male sentenced offenders in 2008. The purpose of this paper is to report on the seven-year retrospective evaluation of the effectiveness of the DSATU. The study consisted of a retrospective analysis of the case files of DSATU participants (2008-09 to 2014-15 fiscal years; $\mathrm{n}=755$ ) and a retrospective, case-control analysis of DSATU program data and Corrections' Case Management Information System (CMIS) data from the Ministry of Justice. DSATU data spanned from 2008-2014, while CMIS data spanned from 2007-2015 (comparator group $\mathrm{n}=535$ ). The effectiveness of the DSATU was measured through Program Fidelity and Treatment Effectiveness, Changes in Institutional Misconduct upon completion of the program, and Changes in Contact with Correctional Services after leaving the correctional facility. Pre- and post-treatment measures of Treatment Effectiveness completed as part of the DSATU program were analyzed. Participants demonstrated statistically significant improvements in their knowledge, beliefs, attitudes, and skills in dealing with substance abuse issues. In the period of time between completing the DSATU program and their release from the RCC, DSATU participants had: a significantly lower rate of Institutional Misconduct (disciplinary offenses) relative to the control group ( $25.3 \mathrm{vs.} 45.8 \%$ ); a significantly lower rate of re-contact with Correctional Services (recidivism) six months (17.3 vs. $26.4 \%$ for the control group) and 12 months ( 28.3 vs. $40.0 \%$ ) post-release; and DSATU participants who came into contact with corrections post-release took longer to do so than those in the control group (251.0 days compared to 158.0 days). This study demonstrated that the DSATU program has been highly effective at reducing recidivism.
\end{abstract}

Key Words Substance abuse treatment; offender rehabilitation; criminogenic needs; criminal recidivism; treatment outcomes.

Journal of CSWB. 2017 Dec;2(3):91-100

www.journalcswb.ca

\section{INTRODUCTION}

The relationship between crime and substance abuse is complex (Bahr, Masters, \& Taylor, 2012; MacKenzie, Mitchell, \& Wilson, 2011; Newsome \& Cullen, 2017; Nordstrom \& Williams, 2012). High rates of recidivism combined with a high frequency of substance abuse problems among offenders underscores the necessity of substance abuse treatment programs for incarcerated offenders (Belenko, Hiller, \& Hamilton, 2013; MacKenzie et al., 2011). Research has shown that pro-criminal attitudes, impulsivity, risk taking, limited self-control, poor problem-solving skills, and lack of education are associated with substance abuse and recidivism (Prendergast, 2009). Addressing addictions issues in isolation is not an adequate, long-term solution for individuals with a history of criminal behaviour (Bahr, Harris, Strobell et al., 2012).
In 2007, a plan to integrate a standardized substance abuse treatment model within adult correctional facilities in Saskatchewan (SK) was initiated, and in 2008 the Dedicated Substance Abuse Treatment Unit(DSATU) became operational. The DSATU is a specialized unit that provides comprehensive in-patient addiction treatment for high-risk male offenders at the Regina Correctional Centre (RCC). The program is a partnership between the SK Ministry of Justice, Corrections and Policing (CP), the Regina Qu'Appelle Health Region (RQHR), and the SK Ministry of Health. This paper shares findings from a larger evaluation that examined the effectiveness of the DSATU.

Program Description

The goals of the DSATU program are to improve access to substance abuse treatment for high-risk, high-need inmates 
sentenced to custody. The DSATU provides a five-week treatment program for up to 20 inmates at a time, with an annual intake of approximately 120 inmates. In addition to the addiction treatment, inmates participate in cultural and life skills programming to enhance treatment outcomes. The curriculum reflects the conceptual models of Cognitive Behavioural Therapy (Marlatt \& Donovan, 2005), Motivational Interviewing (Miller \& Rollnick, 1991), and Criminal Lifestyles Training (Armstrong, 1996). The DSATU program adheres to best practices and research outlined by Health Canada (1999), Correctional Services Canada, and the Canadian Centre on Substance Abuse, and is integrated with the principles of Core Correctional Practice (Andrews, 2001; Andrews \& Bonta, 2006; Andrews \& Kiessling, 1980; Bonta \& Andrews, 2007; Dowden \& Andrews, 2004; Gornik, 2001; Tellier \& Serin, 2001). Additional details regarding the treatment program have been previously reported (Paluck, McCarron, Pandey et al., 2017).

\section{Study Questions}

The goal of this study was to evaluate the effectiveness of the DSATU program by addressing the following questions:

1. Does the DSATU screening and referral process identify suitable participants?

2. Does the treatment program positively impact participant knowledge, beliefs, and attitudes pertaining to substance abuse?

3. Upon completion of the treatment program, do participants demonstrate more positive institutional behaviours?

4. Upon release from the correctional centre, do DSATU participants have decreased contact with correctional services?

\section{Study Design}

Program fidelity pertains to the consistent delivery of the program according to the intended plan. A comprehensive evaluation and monitoring infrastructure is required to ensure that the program does not begin to drift from its original principles (Bechtel \& Pierce, 2011; ODRC, 2008). To that end, a logic model developed by the DSATU Evaluation Sub-Committee prior to the program's implementation served as the framework for the study described in this paper. In addition to the methods described herein, the complete evaluation included a systematic literature review examining the effectiveness of similar substance abuse treatment programs, a literature review of best practices in the field, and online surveys and interviews with program participants, staff, and stakeholders to explore program acceptability (McCarron, Pandey, Paluck et al., 2016).

\section{METHODS}

A retrospective analysis of the case files of DSATU participants (2008-09 to 2014-15 fiscal years) and a case-control analysis of DSATU program data and Corrections' Case Management Information System (CMIS) data from the Ministry of Justice (2007-2015) were conducted.

The CMIS and DSATU databases were linked by Offender ID and time of DSATU participation (for the treatment group) or DSATU screening results (for the control group). A database generated from the linkage of CMIS and DSATU databases was used for all analyses. The linked database included: most serious offense (MSO), aggregate codes and times, drug-related offenses, risk score/category, involvement periods, and time of DSATU participation (for the treatment group) or DSATU screening (for the control group). The study received approval from the Research Ethics Board of the Regina Qu'Appelle Health Region (REB-15-54).

The effectiveness of the DSATU program was measured in three areas:

1. Program Fidelity and Treatment Effectiveness

a) Fidelity of the program screening and assessment process;

b) Completion rate of DSATU participants; and

c) Changes in participants' criminogenic thinking as well as knowledge, beliefs, and attitudes toward substance abuse and addiction.

2. Changes in Institutional Misconduct upon Completion of the Program

a) Number of disciplinary actions and rates of institutional misconduct.

3. Changes in Contact with Correctional Services after Leaving the Correctional Facility

a) Rates of re-contact with correctional services at 6, 12 , and 24 months post-release;

b) Severity of offences resulting in re-contact;

c) Time to re-contact; and

d) Frequency of re-contact with correctional services after leaving the RCC.

\section{Definition of Study Variables}

Institutional misconducts are infractions of the institutions' rules such as a serious breach of security, violence, harm to the safety or well-being of others, or the repetitive violation of the rules that have been reviewed by the Assistant Deputy Director Operations and referred to the appropriate discipline panel for a hearing. It was calculated as a dichotomous (yes/ no) variable.

Re-contact with correctional services is defined as the occurrence of any new legal status where the offender returned to the supervision of Saskatchewan Correctional Services (SCS) following release from RCC. This includes remand, provincial and custody sentences, probation and conditional sentences, and bail and undertakings, but does not include the writing of reports for the courts such as presentence reports. It was calculated as a dichotomous (yes/no) variable at 6,12 , and 24 months.

The time to re-contact is the amount of time that elapsed between the DSATU participants' and control group members' release from RCC and their subsequent contact with SCS. For participants who did not have contact with SCS, the end of the data collection period (October 27th, 2015) was used to define the release period.

The severity of re-contact was determined by the MSO related to subsequent contact with SCS. The Canadian Centre of Justice Statistics, Statistics Canada, in collaboration with its justice-related partners, has established an index to measure the overall seriousness of crime. The index ranks the severity of police-reported crime and covers all Criminal Code 
violations, including traffic as well as drug violations and violations of all federal statutes (Johnson, 2005).

The type of legal status on re-contact identifies the official intervention that is responsible for the subsequent re-contact with corrections. It provides another indication of the seriousness of the criminal behaviour committed by the offender post-release.

Frequency of re-contact is the number of subsequent contacts DSATU participants and control group members have with SCS within the 12 months following their release from custody.

\section{Measures}

\section{Screening and Assessment Tools}

The provision of high intensity treatment programming should be prioritized to inmates who have the highest risk to re-offend (Bahr et al., 2012; Bechtel \& Pierce, 2011; Bogue et al., 2004; Latessa, 2012; Serin, 2005). Matching the intensity and duration of treatment to an offender's degree of risk produces the most effective outcome at the lowest cost (ASCA, 2009; Kopak, Hoffmann, \& Proctor, 2016). Thus, the screening and assessment phases are critical components to a program. Screening is considered to be the initial activity that identifies offenders with addiction problems and potential to re-offend (criminogenic risk factors), while assessment is the process that helps determine the extent of an individual's problem with alcohol and other drugs and the appropriate level of treatment. Screening is a one-time process, whereas assessment should be ongoing throughout treatment (ASCA, 2009; Pearce \& Holbrook, 2002).

In addition to the institutional screening process for criminogenic risk, the DSATU utilizes an additional four screening tools and an assessment interview to determine addiction severity (treatment need) and treatment readiness (Table I). Eligible candidates are then further screened by DSATU program staff, by considering offender age, level of literacy, severity of mental health and/or behavioural issues, and compatibility with other participants. The tools are briefly described below.

The Primary Risk Assessment Tool (PRA) is a component of the Offender Risk Assessment Management System
(ORAMS) and is used to determine the risk to reoffend (i.e., criminogenic risk). It is administered to all sentenced inmates upon entrance into the RCC. The 15-item assessment measure was modeled after the principles of risk, need, and responsivity (Patrick, Orton \& Wormith, 2013). By considering both static and dynamic risk factors, the PRA is able to predict general recidivism in adult offenders. Criminogenic risk levels (i.e., low, medium, high) are assigned to each offender based on their numerical score (Patrick et al., 2013).

The Alcohol Use Questionnaire (previously known as the Alcohol Dependence Severity questionnaire or ADS) is a clinical tool for measuring the severity of alcohol dependence and assessing inmates with alcohol problems. It consists of 25 items that are designed to tap into the alcohol dependence syndrome (Edwards \& Gross, 1976). The term "alcohol dependence syndrome" is part of the original description of the ADS, but this term is no longer in use. The ADS provides a measure of the extent to which the use of alcohol has progressed from psychological involvement to impaired control. This case classification system is supported by previous research, using the aforementioned scale (Skinner \& Horn, 1984). The ADS references the "12-month period prior to arrest" in establishing a severity level.

The Drug Use Questionnaire (DAST 20) was modelled after the Michigan Alcoholism Screening Test (MAST), but is used to assess the severity of problems associated with drug use. Quantitative severity levels of none (0), low (1-5), moderate (6-10), substantial (11-15), and severe (16-20) are based on normative data for the scale (Robinson, Porporino \& Millson, 1991). The DAST 20 includes items concerning frequency of use, symptoms of dependence, extent of drugrelated interference, feelings of guilt, and prior treatment (Boland, Henderson \& Baker, 1998). The DAST also references the "12-month period prior to arrest" in establishing the severity of drug abuse.

The Problems Related to Drinking Scale (PRD) was derived from the MAST. This 15-item scale quantifies the number of problems related to alcohol use. The PRD score is divided into four levels: no substantive alcohol problems (score of 0 ), some problems (1-3), quite a few problems (4-6), and a lot of alcohol problems (7-15) (Kunic \& Grant, 2006).

TABLE I

DSATU program screening and outcome measurement tools

\begin{tabular}{|c|c|c|c|c|}
\hline Tool & Pre-Screening & Screening & Pre-Treatment & Post-Treatment \\
\hline Primary Risk Assessment Tool (PRA) & $\bullet$ & & & \\
\hline Alcohol Dependence Severity (ADS) & & $\bullet$ & & \\
\hline Drug Use Questionnaire (DAST 20) & & $\bullet$ & & \\
\hline Problems Related to Drinking Questionnaire (PRD) & & $\bullet$ & & \\
\hline Treatment Readiness Inventory (TRI) & & $\bullet$ & & \\
\hline Assessment Interview & & $\bullet$ & & \\
\hline Beliefs \& Attitudes about Substance Abuse (BASA) & & & $\bullet$ & $\bullet$ \\
\hline Craving Belief Questionnaire (CBQ) & & & - & $\bullet$ \\
\hline Coping Behaviours Inventory (CBI) & & & $\bullet$ & $\bullet$ \\
\hline Drug Avoidance Self-Efficacy Scale (DASES) & & & $\bullet$ & - \\
\hline Transtheoretical Model of Behavioural Change & & & $\bullet$ & $\bullet$ \\
\hline Program Satisfaction Questionnaire & & & & - \\
\hline
\end{tabular}


The Treatment Readiness Inventory (TRI) (Serin \& Kennedy, 1997) outlines the relative readiness of an inmate to attend a treatment program based on five domains: denial ("I do not have a problem with drinking/drug use"), awareness ("I know I drink/use too much"), resistance ("I do not want anyone telling me what to do about my drinking/using"), acceptance ("People can help me with my drinking/using problems"), and readiness ("I need help now for my drinking/using problems"). The TRI scoring is divided into five levels: non-readiness (0-1.9), low readiness (2-2.8), moderate readiness (3-5.5), positive readiness (6-10), and high readiness (11-15) indicating an excellent prospect who would complete treatment and do very well.

DSATU staff conduct an assessment interview with potential program participants using a 110-item interview guide. The interview gathers information regarding demographic, psychosocial, and situational variables that are used to identify participants who will be a suitable fit for the program and are pertinent to tailoring each participant's treatment plan.

\section{Measures of Treatment Effectiveness}

The DSATU program uses five measures to monitor treatment effectiveness (Table 1). Four measures are administered to program participants within the first week of treatment and again during the last week of treatment. The fifth instrument, a participant satisfaction questionnaire, is administered upon completion of the program.

The Beliefs and Attitudes about Substance Abuse (BASA) Inventory measures many of the commonly-held beliefs about drug and alcohol use. Responses are provided on a 9-point Likert-type scale ranging from completely disagree (1) to completely agree (9). A decrease in the total score on this scale is indicative of improvement (Grant, Kunic, MacPherson et al., 2003).

The Craving Belief Questionnaire (CBQ) measures beliefs about the craving phenomenon. The questions are answered on a 7-point Likert-type scale with responses ranging from totally disagree (1) to totally agree (7). A reduction in the score on this scale indicates improvement (Grant et al., 2003).

The Coping Behaviours Inventory (CBI) was designed to assess the behaviours and thoughts used by alcoholdependent individuals to prevent, avoid, or control the resumption of heavy drinking. The respondent indicates how often he/she uses each coping behaviour in order to avoid relapse. Frequency of use is rated on a four-point scale from 0 (I have usually tried this) to 3 (I have never tried this) (Litman, Stapleton, Oppenheim et al., 1983).

The Drug Avoidance Self-Efficacy Scale (DASES) was developed to assess offenders' self-efficacy in coping with risky situations without the use of drugs. DASES is useful as an outcome measure because scores on the scale have been shown to predict subsequent drug use (Martin, Wilkinson, \& Poulos, 1995).

The DSATU program uses the Transtheoretical Model of Behavioural Change to assess participants' readiness for change along a continuum. The Transtheoretical Model of Behavioural Change is a theoretical framework that describes behavioural change as a process of five stages that individuals must work through (Pre-Contemplation, Contemplation, Preparation, Action, and Maintenance) (Prochaska \& DiClemente, 1983).
As part of the program's quality assurance process, a Participant Satisfaction Questionnaire is completed by all program graduates. The questionnaire has three sections: Program Satisfaction, which consists of eight open-ended questions; Program Delivery, which consists of nine Likerttype questions; and Program Effectiveness, which consists of four Likert-type questions. Only the responses from the Program Effectiveness section of this questionnaire are reported in this paper.

\section{Participants}

DSATU Group: A total of 43 five-week sessions were conducted between 2008 and 2014, which represented 862 cases of participation in the program. Sixty-six individuals did not complete the program. Of the remaining 796 cases, 36 were from individuals who had completed DSATU program more than once. Only the data from their most recent program completion were retained. Thirteen additional cases were omitted because they were missing from either the DSATU or CMIS databases. Ultimately, this left 747 unique cases retained for analysis (Figure 1).

Control Group: Program staff screened an additional 553 inmates who were considered eligible for the treatment program based upon their criminogenic risk assessment (PRA score), but who did not go on to participate in the program. Of these 553 cases, 18 were missing from the CMIS database, leaving 535 valid cases for analysis. Reasons why control group members were not enrolled in the DSATU program are described in Table II.

DSATU participants and controls ranged in age from 18 to 76 years. On average, DSATU participants were slightly older than controls $(\mathrm{M}=34.7$ yrs, $\mathrm{SD}=11.9$ vs. $\mathrm{M}=32.4$, $\mathrm{SD}=11.0), \mathrm{t}(1198)=3.565 ; p=0.99, \mathrm{NS})$. The distribution of participants within their criminogenic risk categories (PRA) was not significantly different between DSATU and control groups ( $\chi^{2}=3.124 ; p=0.21$; NS) (Table III). Therefore, it is reasonable to conclude that the DSATU and control groups were comparable in terms of age and criminogenic risk.

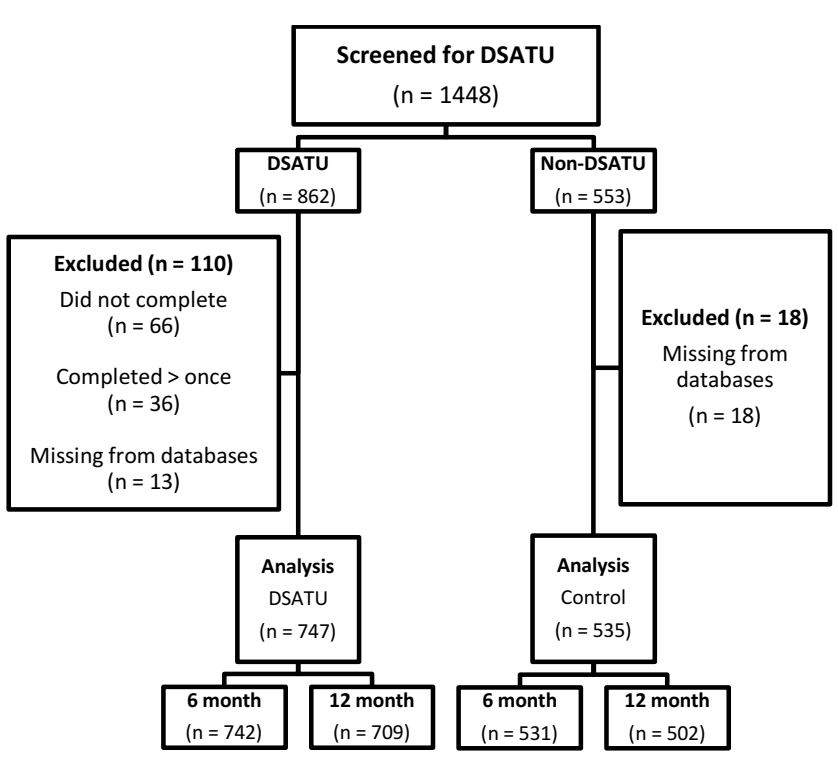

FIGURE 1 Inclusion/exclusion process for DSATU and control groups. 


\section{Statistical Analyses}

Frequency data were used to determine the addiction treatment needs and readiness of participants admitted to the DSATU program, as measured by the screening tools. Paired samples t-tests were conducted to compare participants' pre- and post-treatment scores on all four measures. The Participant Satisfaction Questionnaire was analyzed descriptively. Changes in the frequency and severity of recontact with corrections were also analyzed descriptively using frequencies, means and/or medians, as appropriate. A chi-square test was used to test difference in proportions of re-contact between the DSATU and control groups. Survival distributions were shown with a Kaplan-Meier survival curve to compare differences between the DSATU and control groups for time to re-contact following release from the RCC.

TABLE II Control group participants' reasons for not entering the DSATU

\begin{tabular}{lcc}
\hline \multicolumn{1}{c}{ Reasons } & Frequency & Percent \\
\hline $\begin{array}{l}\text { Excluded based on assessment } \\
\text { tools (ADS, DAST, PRD \& TRI) \& } \\
\text { clinical assessment }\end{array}$ & 172 & 32.2 \\
$\begin{array}{l}\text { Declined treatment } \\
\text { Transferred to another facility or }\end{array}$ & 142 & 26.5 \\
participated in another program & 125 & 23.4 \\
$\begin{array}{l}\text { Behavioural or compatibility issues } \\
\text { Released prior to DSATU start }\end{array}$ & 60 & 11.2 \\
date & 21 & 3.9 \\
No space & 8 & \\
Other & 7 & 1.5 \\
Total & 535 & 100.0 \\
\hline
\end{tabular}

TABLE III Treatment and control group demographics

\begin{tabular}{lcc}
\hline \multicolumn{1}{c}{ Demographics } & $\begin{array}{c}\text { DSATU } \\
\text { (n= 747) }\end{array}$ & $\begin{array}{c}\text { Controls } \\
\text { (n= 535) }\end{array}$ \\
\hline Age (years) & & \\
$\leq 19$ & $5.8 \%$ & $8.6 \%$ \\
$20-29$ & $33.3 \%$ & $46.7 \%$ \\
$30-39$ & $29.7 \%$ & $18.7 \%$ \\
$40-49$ & $20.2 \%$ & $15.9 \%$ \\
$50-59$ & $9.7 \%$ & $7.5 \%$ \\
$\geq 60$ & $1.3 \%$ & $2.6 \%$ \\
Ethnicity & & \\
$\quad$ Non-Aboriginal & $33.3 \%$ & $33.3 \%$ \\
$\quad$ Métis & $7.2 \%$ & $9.0 \%$ \\
$\quad$ Non-Status & $3.1 \%$ & $2.6 \%$ \\
Status & $56.3 \%$ & $54.4 \%$ \\
$\quad$ Unknown & $0.1 \%$ & $0.7 \%$ \\
Criminogenic Risk Category (PRA) & & \\
Low Risk (1 to 5) & $2.7 \%$ & $4.5 \%$ \\
Medium Risk (6 to 11) & $39.9 \%$ & $38.6 \%$ \\
High Risk (12 to 21) & $57.4 \%$ & $56.9 \%$ \\
\hline
\end{tabular}

Cases were right censored if they did not have contact with corrections before the end of the study. The log-rank test was used to statistically compare the survival curves of the two treatment groups. Statistics were calculated using IBM SPSS ${ }^{\circledR}$ Statistics 22.0 (@ IBM Corp., 2013).

\section{RESULTS}

\section{Program Fidelity and Treatment Effectiveness}

\section{Screening and Assessment}

Screening results from the PRD, ADS, and DAST 20 instruments reveal that the vast majority of DSATU participants $(88.2 \% ; \mathrm{n}=666)$ were classified as requiring a high intensity addiction treatment program (Figure 2). Results from the TRI were more variable. One third of participants (36.2\%) were screened as having a positive or high level of treatment readiness (Figure 3), but 175 (23.1\%) participants demonstrated low or no treatment readiness.

\section{Completion rate of the DSATU Program}

Over the seven-year period, a total of 66 participants either withdrew from the program or were removed from the

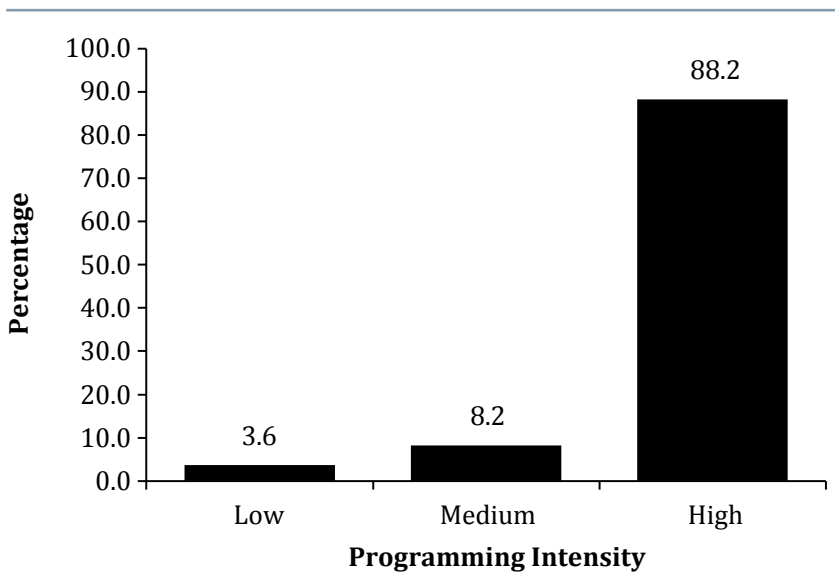

FIGURE 2 Recommended programming intensity for DSATU participants based upon screening and assessment process ( $N=755)$.

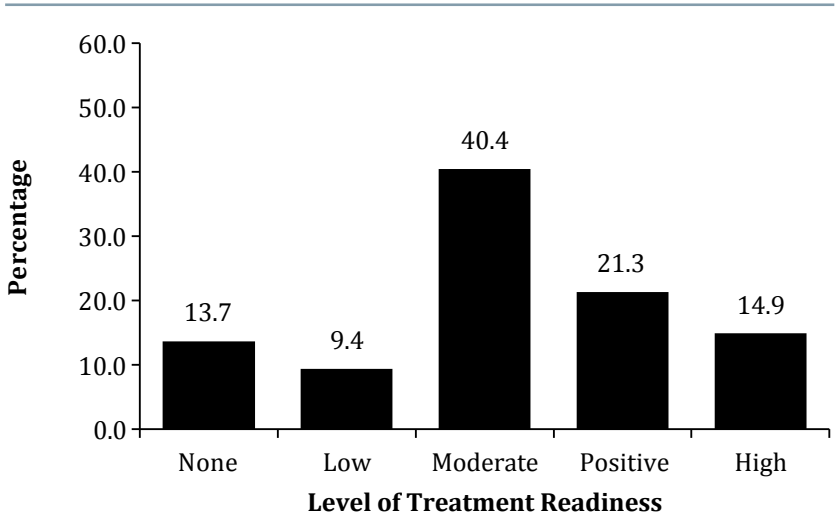

FIGURE 3 Number of participants in each level of treatment readiness, as measured using the TRI ( $N=754$; missing data $=1)$. 
DSATU program, representing a completion rate of $92.3 \%$ (with yearly completion rates ranging from $88.7 \%$ to $95.7 \%$ over the seven-year period). The most common cause for removal from the DSATU program was behavioural issues (44 of the 66 incidents).

\section{Participant Knowledge, Beliefs, and Attitudes}

The pre- and post-treatment measures of treatment effectiveness were analyzed to determine whether participants showed improvement upon completion of the program (Figure 4).

Beliefs and Attitudes about Substance Abuse (BASA) Inventory: There was a significant decrease in BASA scores from pre-treatment $(\mathrm{M}=53.42, \mathrm{SD}=20.49)$ to post-treatment $(\mathrm{M}=37.35, \mathrm{SD}=17.23), \mathrm{t}(741)=-20.14, p<0.001$ (two-tailed). The mean decrease in BASA scores was -16.07 (95\% C.I.: -14.51, -17.94), which is indicative of a positive change in beliefs pertaining to substance use.

Craving Belief Questionnaire (CBQ): There was a statistically significant decrease in CBQ scores from pre-treatment $(\mathrm{M}=62.54, \mathrm{SD}=24.10)$ compared to post-treatment $(\mathrm{M}=45.59$, $\mathrm{SD}=19.22)$, $\mathrm{t}(744)=-18.83, p<0.001$ (two-tailed). The mean decrease in CBQ scores was -16.95 (95\% C.I.: -15.18, -18.83). This decrease indicates that overall, participants hold more accurate beliefs about craving phenomena after they complete the DSATU program.

Coping Behaviours Inventory (CBI): The results show participants' ability to develop coping skills and strategies

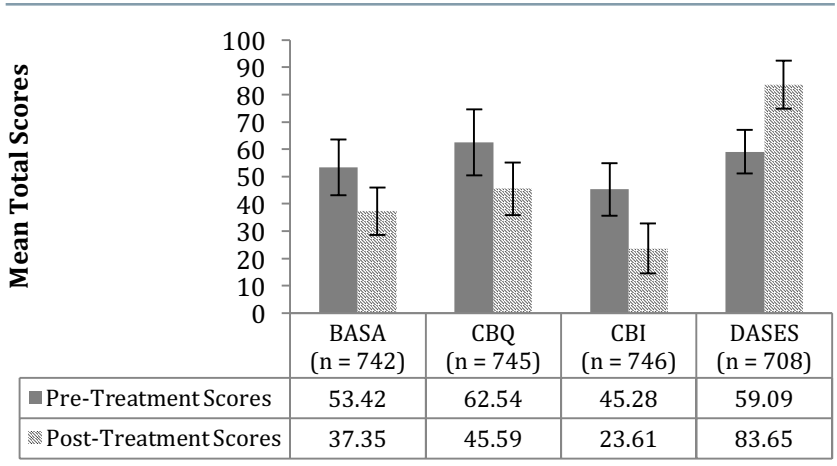

FIGURE 4 Comparison of mean total pre- and post-measures of treatment effectiveness. significantly improved as demonstrated through a reduction in participants' post-treatment CBI scores $(\mathrm{M}=45.28, \mathrm{SD}=$ 19.08) compared to their pre-treatment CBI scores $(\mathrm{M}=23.61$, $\mathrm{SD}=18.31), \mathrm{t}(745)=-26.24, p<0.001$ (two-tailed). The mean decrease in CBI scores was -21.68 (95\% C.I.: -20.06, -23.30).

Drug Avoidance Self-Efficacy Scale (DASES): On average, participants' scores increased from pre-treatment $(\mathrm{M}=$ $59.09, \mathrm{SD}=16.07)$ to post-treatment $(\mathrm{M}=83.65, \mathrm{SD}=17.68)$, $\mathrm{t}(707)=29.10, p<0.001$ (two-tailed). The mean increase in DASES scores was 24.56 (95\% C.I.: 22.91, 26.22). This increase indicates that self-efficacy is enhanced post-treatment, and that participants feel more confident in their ability to cope with situations that put them at risk of relapsing.

Transtheoretical Model of Behavioural Change: The assessment of an inmate's Stage of Change was not measured in the first seven sessions of DSATU programming. Thus, data were not available for 120 participants. The majority of program participants $(n=536)$ entered the treatment program in the contemplation stage. Of the 635 participants who had pre- and post-data available, it was established that 349 showed improvement by moving to the next stage of behavioural change (55.0\%), 283 showed no change (44.6\%), and three participants regressed a level $(0.5 \%)$.

\section{Participant Satisfaction}

Perceived Program Effectiveness: Only 51.7\% $(n=400)$ of program participants reported that they fully understood the concepts and techniques introduced throughout the program (Table IV). However, despite that potential limitation, 71.1\% $(\mathrm{n}=550)$ described the program overall as being very useful and $73.2 \%(n=563)$ rated it as being excellent.

\section{Changes in Institutional Behaviour}

Institutional Misconducts: Upon completion of the DSATU program, participants spent an average of 90 days in the RCC prior to their release. This was used to define the period of interest for the analysis of disciplinary actions. The 90-day period just prior to release was also used for the control group. In the average span of 90 days prior to their release, there were a total of 434 incidents within the correctional centre by both DSATU participants $(n=189)$ and controls $(\mathrm{n}=245)$ that resulted in sanctions by the RCC Disciplinary Panel. The ratio of offenses was significantly lower in DSATU participants than in controls $(25.3 \%$ vs. $45.8 \%)\left(\chi^{2}=58.76 ; \mathrm{df}(1)\right.$ : $p<0.001$, two-tailed).

TABLE IV Descriptive statistics of program effectiveness responses from the Program Satisfaction Questionnaire ${ }^{a}$

\begin{tabular}{|c|c|c|c|c|c|}
\hline \multirow[b]{2}{*}{ Question } & \multicolumn{5}{|c|}{ Program Effectiveness } \\
\hline & 1 & 2 & 3 & 4 & 5 \\
\hline $\begin{array}{l}\text { 1. Now that the program is over, how would you rate the overall } \\
\text { usefulness of the program for you? }(n=774)\end{array}$ & $\begin{array}{c}1 \\
(0.1 \%)\end{array}$ & $\begin{array}{l}6 \\
(0.8 \%)\end{array}$ & $\begin{array}{c}49 \\
(6.3 \%)\end{array}$ & $\begin{array}{c}168 \\
(21.7 \%)\end{array}$ & $\begin{array}{c}550 \\
(71.1 \%)\end{array}$ \\
\hline $\begin{array}{l}\text { 2. Do you feel you are in a better position now to effectively deal with } \\
\text { your substance abuse problem than you were before you started the } \\
\text { program? }(n=773)\end{array}$ & $\begin{array}{c}0 \\
(0.0 \%)\end{array}$ & $\begin{array}{c}2 \\
(0.3 \%)\end{array}$ & $\begin{array}{c}32 \\
(4.1 \%)\end{array}$ & $\begin{array}{c}166 \\
(21.0 \%)\end{array}$ & $\begin{array}{c}573 \\
(72.5 \%)\end{array}$ \\
\hline $\begin{array}{l}\text { 3. How well do you feel you were able to understand the concepts and } \\
\text { techniques introduced throughout the program? }(n=774)\end{array}$ & $\begin{array}{l}3 \\
(0.4 \%)\end{array}$ & $\begin{array}{c}2 \\
(0.3 \%)\end{array}$ & $\begin{array}{c}96 \\
(12.4 \%)\end{array}$ & $\begin{array}{c}273 \\
(35.2 \%)\end{array}$ & $\begin{array}{c}400 \\
(51.7 \%)\end{array}$ \\
\hline 4. Overall, how would you rate this program? $(n=769)$ & $\begin{array}{c}2 \\
(0.3 \%)\end{array}$ & $\begin{array}{c}7 \\
(0.9 \%)\end{array}$ & $\begin{array}{c}44 \\
(5.7 \%)\end{array}$ & $\begin{array}{c}153 \\
(19.9 \%)\end{array}$ & $\begin{array}{c}563 \\
(73.2 \%)\end{array}$ \\
\hline
\end{tabular}

a The rating scale range is 1 (representing a negative response) to 5 (representing a positive response). 


\section{Changes in Contact with Correctional Services}

Re-Contact Rate: Relative to the control group, DSATU participants had a statistically significant lower rate of re-contact at six months (9.1\% lower rate, $\left.\chi^{2}=15.48 ; \mathrm{df}(1) ; p=0.001\right)$. This difference remained statistically significant at both 12 months (11.7\% lower rate; $\left.\chi^{2}=19.20 ; \mathrm{df}(1) ; p<0.001\right)$ and 24 months (5.9\% lower rate; $\chi^{2}=4.37 ; \mathrm{df}(1) ; p=0.04$; Figure 5).

Time to Re-Contact: The median number of days from when a DSATU graduate was released from the RCC until a re-contact with corrections occurred was 251 days $(\mathrm{IQR}=$ 85-418 days). This value was approximately three months (94 days) longer than the median number of days for control group participants (157 days; IQR $=22-293$ ). The survival curve in Figure 6 shows delayed time to re-contact for the DSATU group compared to the control group up to 550 days post-release. One year survival Kaplan-Meier rate estimates of the DSATU group is $70.5 \%(95 \% \mathrm{CI}=67.2-73.9 \%)$ and is $57.8 \%$ (95\% CI $=53.6-62.3 \%)$ for the control group. The log-rank test showed a statistically significant difference in survival curves between the two treatment groups as well, $\chi^{2}=11.6$; $\operatorname{df}(1) ; p<0.0001$. This illustrates that for those inmates who

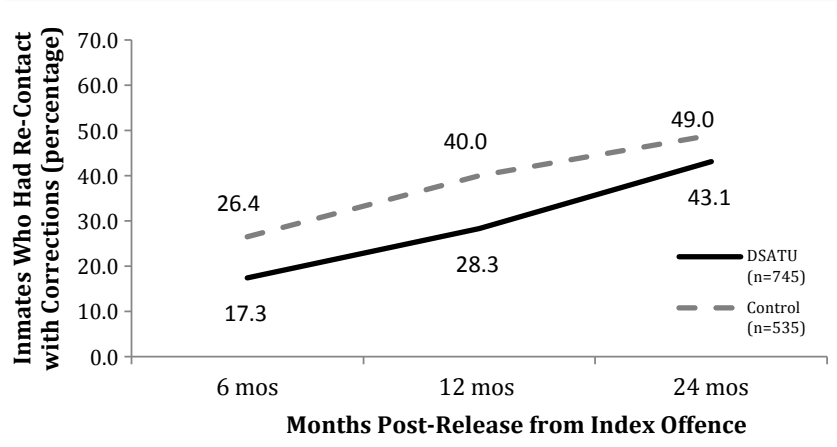

FIGURE 5 Rates of re-contact with Correctional Services within 6, 12 , and 24 months after release from the Correctional Centre.

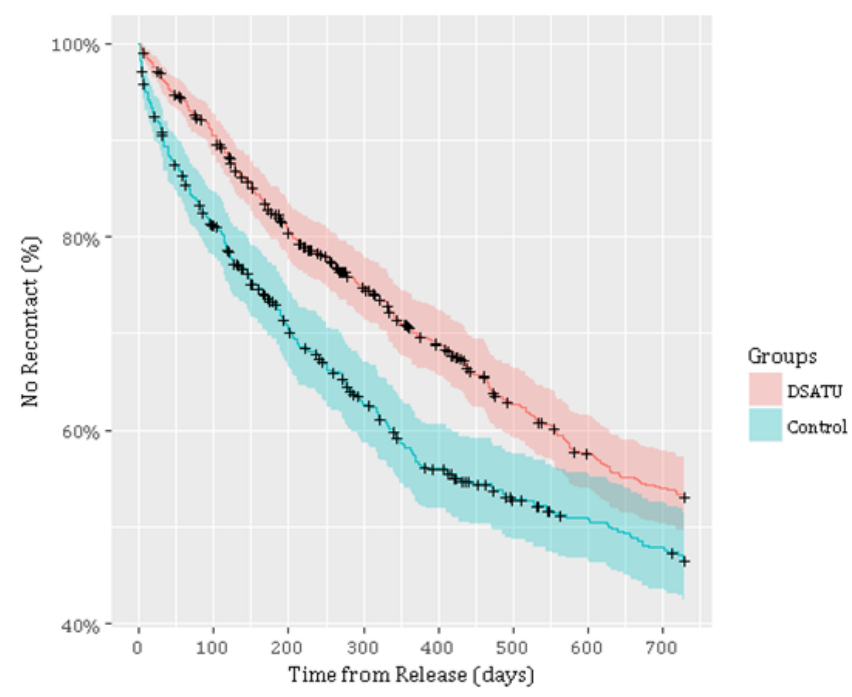

FIGURE 6 Kaplan-Meier curve for re-contact survival rates post institutional release for the DSATU and control groups. Cases that did not reconnect with corrections were censored. had re-contact with the Saskatchewan Corrections, DSATU participants remained in the community longer than the members of the control group before re-contact.

Severity of Re-contact: There were 424 individuals (DSATU $\mathrm{n}=211$, Controls $\mathrm{n}=214$ ) that became re-involved with corrections within 12 months of their release. Relative to their index offence, both the DSATU and control groups demonstrated an improvement in the crime severity ranking of their subsequent offence. The median seriousness ranking of the DSATU group's index offence was 98 and was 109 for their second offence. Control group participants had a median crime severity rating of 87 for their baseline offence and a rating of 108 on their second offence. Higher seriousness rankings reflect less serious offences.

Type of Legal Status on Re-Contact: For the DSATU and control group participants who had re-contact with corrections within 12 months post-release, the majority were placed on remand $($ DSATU $=148$ and control $=134)($ Table V). The differences between the legal status categories were not statistically significant $\left(\chi^{2}=7.368 ; \mathrm{df}(5) ; p=0.75, \mathrm{NS}\right)$.

Frequency of Re-contact: In the 12-month period following their release, 211 DSATU participants and 214 control group members had respective totals of 480 and 483 contacts with Saskatchewan Corrections. While the number of DSATU participants and the controls were similar, DSATU participants had slightly lower frequencies of re-contact during this period. A total of $141(18.7 \%)$ of DSATU graduates and $128(24.0 \%)$ of the controls had two or more contacts with Saskatchewan Corrections in their first 12 months following release; however, this difference was not statistically significant $\left(\chi^{2}=0.887 ; \mathrm{df}(2) ; p=0.64, \mathrm{NS}\right)$.

\section{Limitations}

This study was unable to determine the effectiveness of the DSATU at reducing relapse. As this utilized a retrospective study design, a reliable and valid way of establishing rates of relapse in program participants was not available. To achieve this would have required significant resources at the beginning of the program's implementation to prospectively follow participants and have them self-report (less rigorous) or chemically validate their abstinence.

\section{DISCUSSION}

There has been a considerable shift in the philosophy and management of correctional institutions over the past 40 years (Mackenzie et al., 2011). Incarceration was historically viewed

TABLE V Type of legal status on re-contact (12 months post-release)

\begin{tabular}{lcc}
\hline \multicolumn{1}{c}{ Legal Status } & $\begin{array}{c}\text { DSATU } \\
(\mathbf{n = 2 1 1 )}\end{array}$ & $\begin{array}{c}\text { Control } \\
\text { (n=214) }\end{array}$ \\
\hline Federal Custody Sentence & $1.4 \%$ & $1.4 \%$ \\
\hline Provincial Custody Sentence & $15.2 \%$ & $18.7 \%$ \\
Conditional Supervision & $1.4 \%$ & $3.7 \%$ \\
Remand & $70.1 \%$ & $62.6 \%$ \\
Probation & $5.2 \%$ & $9.8 \%$ \\
Intermittent Sentence & $1.4 \%$ & $0.0 \%$ \\
Bail & $5.2 \%$ & $3.7 \%$ \\
\hline
\end{tabular}


as a punitive measure, with an emphasis on segregating the offender from society resulting in the trend toward mass incarceration. However, this attitude has given way to an orientation toward correctional management that is grounded in the principles of rehabilitation and reintegration into the community. This philosophical shift paved the way for the introduction of a wide variety of vocational, educational, and behavioural treatment programs into correctional facilities.

This shift in philosophy resulted in an increase in the number of substance abuse treatment programs being offered. MacKenzie et al. (2011) observed that by the 1990s, approximately $94 \%$ of federal prisons and most state prisons in the United States provided substance abuse treatment. A similar increase in the number of correctional facility-based programs was also observed in Europe during this period (Kolind, Frank, \& Dahl, 2010). Evaluation of such programs offered in the United States and other countries provides valuable insight into the effectiveness of these programs in reducing recidivism and relapse. However, in the early years, there was no consensus as to what the best practices were, and many of the programs lacked a solid theoretical, evidence-based foundation (Weekes \& Thomas, 2004). Over time, the evidence base grew and a number of resources providing guidance on best practices and treatment guidelines became available (e.g., ASCA, 2009; Bechtel \& Pierce, 2011; Bogue, Campbell, Clawson et al., 2004; Latessa, 2012; Pearce \& Holbrook, 2002; Serin, 2005). However, research evaluating the effectiveness of these programs remained challenged due to weak study designs and a low uptake of evidence-based treatment models within facilities (Belenko et al., 2013).

In Canada, the results of a comprehensive evaluation of all federal treatment programs administered by Correctional Service of Canada (CSC) were released in 2009 (Nafekh, Allegri, Stys et al., 2009). Among the programs, the High Intensity National Substance Abuse Program for high risk/high need offenders was deemed to be cost-effective and instrumental in contributing to reductions in criminal behaviour post-release. There have been other evaluations of CSC substance abuse treatment programs (Delnef, 2001) providing similar evidence regarding treatment effectiveness. However, in 2015 when our efforts to formally evaluate the DSATU program got underway, we were unable to identify reports of treatment programs for high-risk, high-need male adult offenders in a provincial correctional facility (Pandey, McCarron, Paluck et al., 2016). Thus, the primary purpose of this paper was to share the findings of the DSATU evaluation and contribute to the searchable evidence in this area.

Best practices in corrections-based substance abuse treatment indicate that high-intensity programs such as the DSATU be reserved for inmates at the highest risk to re-offend, the reason being that providing high-intensity services to low-risk inmates can result in an increase in recidivism (Bechtel \& Pierce, 2011; Bahr et al. 2012; Latessa, 2012). This study found that the majority of DSATU program participants were screened as being at medium- (39.9\%) or high-risk $(57.4 \%)$ to reoffend. The vast majority of these inmates (88\%) were assessed by counsellors and recommended for a "high" intensity program based upon the severity of their addiction and readiness to receive treatment.

Our evaluation revealed that DSATU participants demonstrated statistically significant changes in their pre- and post-scores of knowledge, attitude, and behaviours. While the scientific literature provides no guidance on the amount of change that is required to achieve clinically significant results in terms of relapse prevention, a more recent study identified some preliminary support for an inverse relationship between the rates of re-contact and the amount of change in pre/post test scores (Simourd, Olver, \& Brandenburg, 2016).

DSATU participants who came into contact with corrections post-release took longer to do so than those in the control group. It is difficult to compare the results of the DSATU to similar programs in other jurisdictions because the definition of 'recidivism' is inconsistent, and the weak study design of many published studies dilutes their generalizability (Belenko et al., 2013). The systematic review conducted as part of the full evaluation of the DSATU found that $26 \%$ of studies meeting our inclusion criteria were classified as "poor" or "low quality" and could not be considered (Pandey et al., 2016). Acknowledging this limitation, it appears that participation in the DSATU has an equal, if not greater impact on recidivism relative to other programs reported in the literature (Pandey et al., 2016). However, the absence of a pre-treatment phase and access to a structured aftercare component that addresses criminogenic risk factors (in addition to addiction issues) were two best practice guidelines (Latessa, 2012) that were not fulfilled by the DSATU program. The impact this has had on the DSATU's effectiveness is unknown.

Interestingly, the control group in this study also demonstrated improvements in many of the study variables we examined. It is possible that, while the improvements demonstrated by the DSATU reflect the impact of the high-intensity addictions treatment program, the improvements observed in the control group reflect the effectiveness of the core correctional practices and general programming considered to be standard work in Saskatchewan Corrections. The expansion of other evidence-based programming and treatments, which facilitates access for a greater number of offenders, is considered essential in attempting to reverse the effects of wide-scale incarceration (Taxman, Pattavina, \& Caudy, 2014).

\section{CONCLUSIONS}

To the best of our knowledge, the Dedicated Substance Abuse Treatment Unit at the Regina Correctional Centre was the first of its kind in Canada when it was implemented in 2008. The results of this study validate those reported in the literature stating that multi-modal substance abuse treatment programs, targeted to the right participant, are effective at reducing re-contact with the correctional system. The partnership necessary to operationalize this program was innovative and the resulting program is effective, sustainable, and likely transferable to other correctional facilities wishing to offer this type of programming.

\section{ACKNOWLEDGMENTS}

The authors wish to acknowledge the support of the Regina Qu'Appelle Health Region and the ongoing guidance from current and past members of the DSATU Evaluation Sub-Committee Working Group. A special thank you to Lorri Carlson, Executive Director, Mental Health \& Addictions Services, RQHR; Brian Danyliw, Director, Addictions Services, RQHR; Doris Schnell, Executive Director, Offender Services CP, Ministry of Justice; and long-time members of the Governance Committee for their invaluable contributions. 


\section{CONFLICT OF INTEREST DISCLOSURES}

Financial support for the program evaluation was provided by the Dedicated Substance Abuse Treatment Unit (DSATU) Governance Committee, Regina, SK. An abstract of the Program Evaluation findings from this study was presented at the Canadian Centre on Substance Use and Addiction, Issues of Substance Abuse Conference (November 2017).

\section{AUTHOR AFFILIATIONS}

*Research and Performance Support, Regina Qu'Appelle Health Region, Regina, SK; Ministry of Justice, ${ }^{+}$Corrections and Policing, Government of Saskatchewan, Regina, SK.

\section{REFERENCES}

Andrews, D. A, (2001). Principles of effective correctional treatment. In L.L. Motiuk \& R.C. Serin (Eds.), Compendium 2000 on effective correctional programming (pp. 9-17). Ottawa, ON: Correctional Service of Canada.

Andrews, D. A, \& Bonta, J. (2006). The psychology of criminal conduct (4th ed.). Newark, NJ: Lexis Nexis.

Andrews, D. A, \& Kiessling, J. J. (1980). Program structure and effective correctional practices: A summary of the CaVIC research. In R.R. Gendreau \& P. Ross (Eds.), Effective correctional treatment. Toronto, ON: Butterworths.

Armstrong, B. (1996). Lifestyles participant's manual [Manual]. Ottawa, ON: Criminal Thinking Program.

Association of State Correctional Administrators Substance Abuse Committee (ASCA). (2009). Recommended practices-Substance abuse treatment in correctional settings. Nampa, ID: The Association.

Bahr, S. J., Harris, P. E., Strobell, J. H., \& Taylor, B. M. (2012). An evaluation of a short-term drug treatment for jail inmates. International Journal of Offender Therapy \& Comparative Criminology, 57(10),1275-1296.

Bahr, S. J., Masters, A. L., \& Taylor, B. M. (2012). What works in substance abuse treatment programs for offenders? The Prison Journal, 92(2), 155-174.

Bechtel, K. \& Pierce, B. A. (2011). An overview of what works in correctional interventions. Boston, MA: Crime and Justice Institute. Retrieved from http://b.3cdn.net/criustice/aac3cda45ab8784552_ogm6bn2pd.pdf

Belenko, S., Hiller, M, \& Hamilton, L. (2013). Treating substance use disorders in the criminal justice system. Current Psychiatry Report, 15(11).

Bogue, B., Campbell, N., Clawson, E., Faust, D., Florio, K., Joplin, L., .. Woodward, W. (2004). Implementing evidence-based practices in community corrections: The principles of effective intervention. Washington, DC: Department of Justice, National Institute of Corrections.

Boland, F. J., Henderson, K., \& Baker, J. (1998). Case needs review: Substance abuse domain. Ottawa, ON: Correctional Service Canada (R-76).

Bonta, J. \& Andrews, D. A, (2007). Risk-Need-Responsivity model for offender assessment and rehabilitation (User report No. 2007-06). Ottawa, ON: Public Safety Canada.

Delnef, C. (2001). Correctional Service of Canada Substance Abuse Programs: OSAPP, ALTP, and Choices. Forum on Corrections Research Focusing on Alcohol and Drugs, 13(3), 35-40

Dowden, C., \& Andrews, D. A. (2004). The importance of staff practice in delivering effective correctional treatment: A meta-analysis review of core correctional practice. International Journal of Offender Therapy and Comparative Criminology, 48(2), 203-214.

Edwards, G., \& Gross, M. M. (1976). Alcohol dependence: Provisional description of a clinical syndrome. British Medical Journal, 1(6017), 1058-1061.

Gornik, M. (2001). Moving from correctional program to correctional strategy: Using proven practices to change criminal behaviour. Boulder, CO: National Institute of Corrections.

Grant, B., Kunic, D., MacPherson, P., McKeown, C., \& Hansen, E. (2003). The high intensity substance abuse program (HISAP): Results from the pilot programs [Research Report]. Ottawa, ON: Addictions Research Centre, Research Branch, Policy Planning and Coordination, Correctional Service Canada.
Health Canada, Office of Alcohol, Drugs and Dependency Issues. (1999) Health Canada best practices substance abuse treatment and rehabilitation. Ottawa, ON: Minister of Public Works and Government Services, Cat. No.: H39-438/1998E.

Johnson, S. (2005). Returning to Correctional Service after release: A profile of Aboriginal and non-Aboriginal adults involved in Saskatchewan Corrections from 1999/200 to 2003/04. Juristat, 25/2).

Kolind, T., Frank, V. A., \& Dahl, H. (2010). Drug treatment or alleviating the negative consequences of imprisonment? A critical view of prison-based drug treatment in Denmark. International Journal of Drug Policy, 21(1), 43-48.

Kopac, A. M, Hoffmann, N. G., \& Proctor, S. L. (2016). Key factors for relapse and rearrest among substance use treatment patients involved in the criminal justice system. American Journal of Criminal Justice, 41(1):14.

Kunic, D., \& Grant, B. (2006). The computerized assessment of substance abuse (CASA): Results from the demonstration project [Research Report]. Ottawa, ON: Addictions Research Centre, Correctional Service of Canada.

Latessa E.J. (2012). Designing more effective correctional programs using evidence based practices. Tokyo, Japan: United Nations Asia and Far East Institute for the Prevention of Crime and the Treatment of Offenders (UNAFEI). Resource Material Series No. 88; 151 st International Training Course visiting experts' papers.

Litman, G. K., Stapleton, J., Oppenheim, A. N., \& Peleg, M. (1983). An instrument for measuring coping behaviours in hospitalized alcoholics: Implications for relapse prevention treatment. British Journal of Addiction, 78(3), 269-276.

MacKenzie, D. L., Mitchell, O., \&Wilson, D. B. (2011). The impact of drug treat ment provided in correctional facilities. In C. Leukefeld, T.P. Gullotta, \& J. Gregrich (Eds.), Handbook of evidence-based substance abuse treatment in criminal justice settings (pp. 183-203). New York: SpringScience + Business Media.

Marlatt, G. A. \& Donovan D. M. (2005). Relapse prevention: Strategies in the treatment of addictive behaviours. New York, NY: Guilford Press

Martin, G. W., Wilkinson, D. A., \& Poulos, C. X. (1995). The Drug Avoidance Self-Efficacy Scale. Journal of Substance Abuse. 7(2), 151-163.

McCarron, M. C. E., Pandey, M., Paluck, E., \& Banka, D. (2016) An evaluation of the Dedicated Substance Abuse Treatment Program (DSATU) at the Regina Correctional Centre: Observations and insights from program participants, staff, and stakeholders. Regina, SK: Regina Qu'Appelle Health Region.

Miller, W. R., \& Rollnick, S. (1991). Motivational interviewing: Preparing people to change addictive behavior. New York, NY: Guilford Press.

Nafekh, M., Allegri, N., Stys, Y., \& Jensen, T. (2009). Evaluation report: Correctional Service Canada's correctional programs. Retrieved from Correctional Service Canada website: http://www.csc-scc.gc.ca/text/ $\mathrm{pa} / \mathrm{cop}$-prog/cp-eval-eng.shtml

Newsome, J. \& Cullen, F.T. (2017). The risk-need-responsivity model revisited. Using biosocial criminology to enhance offender rehabilitation. Criminal Justice and Behaviour, 44(8), 1030-1049.

Nordstrom B. R., \& Williams, A. R. (2012). Drug treatments in criminal justice settings. Psychiatric Clinics of North America, 35(2), 375-391.

Ohio Dept. of Rehabilitation and Correction (ODRC). (2008). Best Practices Tool Kit: Community Corrections and Evidence based Practices. Columbus, $\mathrm{OH}$ : Ohio State Dept. of Rehabilitation and Correction.

Paluck, E., McCarron, M. C. E., Pandey, M., \& Banka, D. (2017). An innovative service collaboration to reduce criminal recidivism for inmates with severe addictions. Journal of Community Safety \& Well-Being, 2(2), 66-70.

Pandey, M., McCarron, M. C. E., Paluck, E., \& Banka, D. (2016). Effectiveness of substance abuse treatment programs at correctional facilities: A systematic literature review. Regina, SK: Regina Qu'Appelle Health Region.

Patrick, G., Orton, L., \& Wormith, S. (2013). The predictive validity of the Saskatchewan Primary Risk Assessment (SPRA) (Research Report). Saskatoon, SK: Centre for Forensic Behavioural Science and Justice Studies, University of Saskatchewan. 
Pearce, S. C., \& Holbrook, D. (2002). Research findings and best practices in substance abuse treatment for offenders: A review of the literature. Raleigh, NC: North Carolina Department of Correction, Office of Research and Planning

Prendergast, M.L. (2009). Interventions to promote successful re-entry among drug-abusing parolees. Addiction Science \& Clinical Practice, 5(1), 4-13.

Prochaska, J., \& DiClemente, C. (1983). Stages and processes of self-change in smoking: toward an integrative model of change. Journal of Consulting and Clinical Psychology, 5, 390-395.

Robinson, D., Porporino, F. J., \& Millson, W. A. (1991). Patterns of alcohol and drug use among federal offenders as assessed by the Computerized Lifestyle Screening Instrument. Ottawa, ON: Correctional Service of Canada.

Serin, R. (2005). Evidence based practice: Principles for enhancing correctional results in prisons. Ottawa, ON: National Institute of Corrections.

Serin, R., \& Kennedy, S. (1997). Treatment readiness and responsivity: Contributing to effective correctional programming. Ottawa, ON: Correctional Service of Canada.
Simourd, D. J., Olver, M. E., \& Brandenburg, B. (2016). Changing criminal attitudes among incarcerated offenders: initial examination of a structured treatment program. International Journal of Offender Therapy and Comparative Criminology, 60(12), 1425-1445.

Skinner, H. A., \& Horn, J. L. (1984). Alcohol Dependence Scale (ADS): User's guide. Toronto, ON: Addiction Research Foundation.

Skinner, W. J. W. (Ed). (2005). Treating concurrent disorders: A guide for counsellors. Toronto, ON: Centre for Addiction \& Mental Health.

Taxman, F. S., Pattavina, A., \& Caudy, M. (2014). Justice reinvestment in the United States: an empirical assessment of the potential of increased correctional programming on recidivism. Victims and Offenders, 9(1):50-75.

Tellier, C., \& Serin, R. C. (2001). The role of staff in effective program delivery. In L. L. Motiuk \& R. C. Serin (Eds.), Compendium 2000 on effective correctional programming (pp. 174-184). Ottawa, ON: Correctional Service of Canada.

Weekes, J., Thomas, G, \& Graves, G. (2004). Substance abuse in corrections: FAQs. Ottawa, ON: Canadian Centre on Substance Abuse. 